\title{
Comparison between Mammography and Breast Ultrasound in the Detection of Breast Cancer in Dense Breast Tissue among a Sample of Iraqi Women
}

DOI: https://doi.org/10.32007/88925-29

\author{
Hiba M. AbdulWahid* CABMS
}

(c) (1) (8)

This work is licensed under a Creative Commons Attribution-NonCommercial 4.0 International License.

Abstract:

Background: Breast cancer is the most common cancer reported in women worldwide. In Iraq, it is the most common registered malignancy. Mammography plays a major role in the early detection of breast cancers. Dense breast parenchyma has been reported to be the most important inherent factor that limits depiction of breast cancer on mammogram, and often needs supplementary breast ultrasound for complete assessment.

Objectives: To evaluate and compare the diagnostic performance of mammography and ultrasound in the detection of breast cancer in dense breast tissue.

J Fac Med Baghdad 2019; Vol.61, No.1 Received Mar. 2018 Accepted June 2019 Published: July, 2019
Patients and methods: A record review study was performed in the Oncology Teaching Hospital/ Medical City from April 2018 to December 2018. The study included forty five females, who attended the Main Referral Center for Early Detection of Breast Tumors during 2017 and 2018 were diagnosed with breast cancer histopathologically. They had dense breast tissues on mammography (either heterogeneously dense breast tissue i.e. category $\mathrm{C}$ or extremely dense breast tissue i.e. category D). All patients underwent subsequent breast ultrasound.Their information including the mammogram findings, breast ultrasound, fine needle aspiration (FNA) and biopsy results were reviewed analyzed and compared.

Results: Twenty four patients $(53.3 \%$ ) had heterogeneously dense breast tissue (ACR category C) and 21 patients $(46.6 \%)$ had extremely dense breast tissue (ACR category D). The mammogram detected 36 from 45 breast cancers $(80 \%)$ while $9(20 \%)$ were not detected by mammogram, so the mammogram had a detection rate of breast cancer of $80 \%$ in mammographically dense breast, while breast ultrasound had higher detection rate of about $97.7 \%$. The sensitivity of mammography in extremely dense breast tissue was about $71 \%$ and in heterogeneously dense breast was about $87 \%$ while ultrasound had shown a higher sensitivity with increasing tissue density ( $98 \%$ vs. $100 \%)$.

Conclusion: Breast cancer can be easily obscured and missed in mammographically dense breast tissue due to overlapping surrounding fibroglandular tissue and additional complementary breast ultrasound is highly recommended for a thorough evaluation and to depict mammographically occult breast carcinoma.

Keywords: mammography, ultrasound, dense breast tissue, obscured breast cancer.

\section{Introduction:}

Breast cancer is the most common cancer reported in women worldwide, accounting for $16 \%$ of all female malignancies $(1,2)$. Previous studies from Iraq have reported that breast cancer is the most common registered malignancy (3) and most of the cases are often reported in middle aged women (4).Mammography plays a major role in the early detection of breast cancers, detecting about $75 \%$ of cancers at least a year before they can become symptomatic $(5,6)$. Missed breast cancers on mammogram may be attributed to several factors which include dense breast parenchyma that may obscures a small lesion, poor patient positioning or improper technique, misinterpretation of a suspicious

* National Cancer Research Center, University of Baghdad. Email: dr.hiba.mohammed85@Gmail.com breast lesion as benign, errors of perception, gradual growth of a lesion, and subtle features of malignancy

(7). Dense breast parenchyma has been reported to be the most important inherent factor that limit depiction of breast cancer on mammography, and often needs supplementary breast ultrasound for complete assessment (8).Furthermore, dense breast tissues by itself is associated with increased risk of breast malignancy and also reduces the sensitivity of mammogram in cancer detection to as low as $30-48 \%$ (9). Breast density is the relative amounts of glandular tissue and fat in the breast and it ranges from nearly completely fatty tissue to nearly completely fibroglandular tissue, which affects the appearance of the breast on mammograms. The American College of Radiology (ACR) -Breast Imaging Reporting and Data System (BI-RADS) Atlas had classified breast density 
into four categories (7). Breast tissue that is almost entirely fatty is classified as category A, scattered fibroglandular tissue classified as category B, heterogeneously dense breast tissue as category $\mathrm{C}$ and extremely dense breast tissue as category D.

\section{Patients and Methods:}

A retrospective record review was performed in the Oncology Teaching Hospital/ Medical City in Baghdad from April 2018 to December 2018. The study included forty five females, who attended the Main Referral Center for Early Detection of Breast Tumors during 2017 and 2018 and diagnosed with breast cancer histopathologically. They had dense breast tissue on mammogram (either heterogeneously dense i.e. category $\mathrm{C}$ or extremely dense breast tissue i.e. category D).Their information including the mammogram findings, breast ultrasound, FNA and biopsy results were reviewed analyzed and compared.

All mammogram were performed using the Analoge mammogram-Seimens.Two mammographic views were taken; craniocaudal and mediolateral oblique views. The mammographic images were analyzed by a specialist radiologist. The mammographic findings are recorded according to the BIRADS lexicon and include: Any detectable breast mass and its morphology(shape, margin, density, site ),microcalcifications (grouped , scattered, regional,...), an architectural distortion ,skin thickening , nipple retraction ,etc.....

The mammogram findings of those patients were either: No detectable abnormality because the breast density obscured it and further evaluation is needed, focal asymmetry, findings that were suspicious for malignancy such as architectural distortion, grouped microcalcification, etc.... and mammographic findings that are highly suggestive of malignancy i.e. an irregular radiodense mass. Complementary breast ultrasound was done for all patients by a specialist radiologist. The ultrasound findings were subsequently performed and the findings were classified. Ultrasound-guided FNA had been performed for all patients and then biopsied .The corresponding cytological and histopathological results were registered.

\section{Inclusion criteria:}

Women aging 35 years old and older with dense breast tissue (category $\mathrm{C}$ and $\mathrm{D}$ ) were included.

\section{Exclusion criteria:}

Women on hormone replacement therapy.

Lactating and pregnant women.

Postoperative cases.

\section{Statistical analysis:}

The collected data were tabulated and analyzed using Microsoft Excel 2010.The categorical data were presented as frequency and percentage tables.

\section{Results}

Forty five female patients with dense breast tissue (ACR breast density category $\mathrm{C}$ or $\mathrm{D}$ ) and with histopathologically proven breast cancer were included. All patients had breast ultrasound and mammogram. Twenty four patients (53.3\%) had heterogeneously dense breast tissue (ACR category C) and 21 patients (46.6\%) had extremely dense breast tissue (ACR category D). The mean age of the patients was 44.5 years, ranging from ( 35 to 62 years). The mammogram detected 36 out of 45 breast cancers $(80 \%)$ while 9 (20\%) were not detected by mammogram. Of these nine patients, 6 had extremely dense breast (category D) and 3 had heterogeneously dense breast tissue (category C). No mammographic abnormality was detected in seven of 9 cases. The other two cases appeared as an area of focal asymmetry on mammogram. All these overlooked breast cancers on mammography were detected by subsequent ultrasound examination, which revealed features suggestive of malignancy (BI-RADS IV \& V) and all proved to be malignant by subsequent histopathological study. The characteristics of breast cancer not depicted by mammogram are summarized in table 1 .

Table 1: The characteristics of breast cancer cases not detected by mammogram

\begin{tabular}{|c|c|c|c|c|c|}
\hline cases & $\begin{array}{l}\text { Age } \\
\text { (Years) }\end{array}$ & BI-RADS density & Mammography findings & $\begin{array}{l}\text { Maximal Tumor size by } \\
\text { US (mm) }\end{array}$ & US BI-RADS \\
\hline 1 & 41 & $\mathrm{D}$ & focal asymmetry & 8 & BIRADS IV \\
\hline 2 & 38 & $\mathrm{D}$ & No detectable abnormality & 15 & BIRADS V \\
\hline 3 & 55 & $\mathrm{C}$ & No detectable abnormality & 18 & BIRADS V \\
\hline 4 & 40 & $\mathrm{C}$ & No detectable abnormality & 9 & BIRADS IV \\
\hline 5 & 45 & $\mathrm{C}$ & focal asymmetry & 10 & BIRADS IV \\
\hline 6 & 35 & $\mathrm{D}$ & No detectable abnormality & 13 & BIRADS V \\
\hline 7 & 43 & $\mathrm{D}$ & No detectable abnormality & 14 & BIRADS V \\
\hline 8 & 36 & $\mathrm{D}$ & No detectable abnormality & 16 & BIRADS V \\
\hline 9 & 52 & $\mathrm{D}$ & No detectable abnormality & 10 & BIRADS V \\
\hline
\end{tabular}


The 36 detected breast cancer on mammogram (80\%); appeared as an irregular radiodense mass in 13 cases (28.8\%), a radiodense mass with partially obscured margin in 11 cases $(24.4 \%)$, grouped malignant appearing microcalcifications in 5 cases $(11.1 \%)$, grouped microcalcifications with architectural distortion in 4 cases $(8.88 \%)$, only architectural distortion in one case (2.2\%), and a thickened skin with edematous breast tissue in two cases (4.44\%). Malignant features were detected in breast ultrasound of all of these cases except one which appeared on mammography as an area of architectural distortion.

Table 2: Appearance of detected breast cancer on mammography

\begin{tabular}{lll}
\hline Mammographic findings & NO. & Percentage* \\
\hline $\begin{array}{l}\text { Irregular spiculated radiodense mass } \\
\text { radiodense mass with partially } \\
\text { obscured margin }\end{array}$ & 13 & $13 / 45(28.8 \%)$ \\
\hline $\begin{array}{l}\text { Grouped microcalcification } \\
\text { +architectural distortion }\end{array}$ & 4 & $4 / 45(8.88 \%)$ \\
\hline Grouped microcalcification & 5 & $5 / 45(11.1 \%)$ \\
\hline Architectural distortion & 1 & $1 / 45(2.2 \%)$ \\
\hline $\begin{array}{l}\text { Thickened skin with edematous breast } \\
\text { parenchyma }\end{array}$ & 2 & $2 / 45(4.44 \%)$ \\
\hline TOTAL & 36 & $36 / 45(80 \%)$ \\
\hline
\end{tabular}

* Calculated out of a total of 45 cases

In this study, mammography had a detection rate of breast cancer of $80 \%$ in mammographically dense breast, while breast ultrasound had the higher detection rate of about $97.7 \%$. Similarly, the sensitivity of breast ultrasound in heterogeneously dense breast and extremely dense breast was found to be higher than mammography. In the current study, the sensitivity of mammography in extremely dense breast tissue was about $71 \%$ and in heterogeneously dense breast was about $87 \%$ while ultrasound had shown a higher sensitivity with increasing tissue density (98\% VS $100 \%)$. Sensitivity was measured based on histopathological results as the gold standard.

\section{Discussion}

Previous studies evidence revealed that mammography can depict breast malignancy early in apparently healthy women aging 50 to 70 years and subsequently decreasing the mortality rates from breast cancer. Mammography, however, is not so perfect to depict all breast cancers and may miss some cancers in certain cases, particularly in dense breasts. In those women with dense breasts, the normal breast parenchyma and the tumor are difficult to differentiate from each other mammographically. For this reason, some supposed that the addition of ultrasound for those women along with the mammography will detect these tumors that are obscured and missed by mammography alone (10).
In the current study, 24 patients (53.3\%) had heterogeneously dense breast tissue (ACR category C) and 21 patients $(46.6 \%)$ had extremely dense breast tissue (ACR category D). The mammogram detected 36 out of 45 breast cancer cases, missing 9 cases, so the detection rate of the mammogram in this study was $80 \%$. This was in agreement with the study of Okello J. et al in which mammograms detected about 16 out of 22 breast cancer cases, missing six cases, with the detection rate of mammogram of $73 \%$ (11). Breast ultrasound had a higher detection rate of about $97.7 \%$ in dense breast tissue in this study.

Similarly, this study showed that the sensitivity of mammogram in heterogeneously dense breast was $87 \%$ and in extremely dense breast tissue was $71 \%$,i.e. ; decreasing mammographic sensitivity with increasing breast density, while ultrasound had a higher sensitivity with increasing tissue density ( $98 \%$ in heterogeneous dense breast VS 100\% in extremely dense breast) . These results were in accordance with those of Disha et. al. and many other previous studies (12-15).

Two cases of breast cancer which appeared on mammogram as focal asymmetry (i.e. no typical malignant features were present), the ultrasound had showed an ill-defined hypoechoic area at corresponding region (US BIRADS IV) and subsequently proved to be malignant histopathologically. This was in agreement with what was reported by Samarder et.al. in that focal asymmetrical breast density although is repeatedly seen at mammography and usually due to overlapping fibroglandular tissue but sometimes it is due to a hidden malignancy (16).

All obscured breast cancer cases on mammogram in this study were less than $20 \mathrm{~mm}$ in maximal diameter when subsequently evaluated by ultrasound and these represent early stage of breast cancer which expected to have favorable prognosis . These findings were in accordance with what was reported by Okello et.al (11).

\section{Conclusion:}

Breast cancer can be easily obscured and missed in mammographically dense breast tissue due to overlapping surrounding fibroglandular tissue. Additional complementary breast ultrasound is highly recommended for a thorough evaluation and to depict mammographically occult breast carcinoma.

\section{Acknowledgement:}

Great thanks to the staff working in the Radiology and Pathology Departments of the Oncology Teaching Hospital and the Main Referral Center for Early Detection of Breast Tumors for their help and support. 


\section{References}

1. Bray F, Ferlay J, Soerjomataram I et.al. Global Cancer Statistics 2018: GLOBOCAN Estimates of Incidence and Mortality Worldwide for 36 Cancers in 185 Countries. Cancer J Clin. 2018; 68:394-424.

2. World Health Organization. Breast cancer: prevention and control. Available at:http://www.who.int/cancer/detection/ breast cancer/en/index.html 2011.

3. Annual Report. Iraqi Cancer Registry 2015. Iraqi Cancer Board, Ministry of Health and Environment, Republic of Iraq, 2018.

4. Alwan NAS. Breast Cancer among Iraqi women: Preliminary Findings from a Regional Comparative Breast Cancer Research Project. Journal of Global Oncology, ASCO, 2016; 2 (1): 1-4.

5. Etzioni, R.; Urban, N.; Ramsey, S.; et al .The case for early detection. Nat. Rev. Cancer 2003, 3, 243-252. 6. Arleo, E.K.; Hendrick, R.E.; Helvie, M.A.; et al. Comparison of recommendations for screening mammography using CISNET models. Cancer 2017, 123, 3673-3680.

7. D'Orsi, C.J.; Sickles, E.A.; Mendelson, E.B. ACR BI-RADS® Atlas, Breast Imaging Reporting and Data System; American College of Radiology: Reston, VA, USA, 2013.

8. Kelemen LE, Pankratz VS, Sellers TA: Age-specific trends in mammographic density: the Minnesota breast cancer family study. Am J Epidemiol 2008, 167:10271036.

9. Hersh MR: Imaging the dense breast. Applied Radiology 2004, 33:22.
10. Gartlehner $G$, Thaler $K$, Chapman A, et al . Mammography in combination with breast ultrasonography versus mammography for breast cancer screening in women at average risk (Review). Cochrane Database of Systematic Reviews. 2013; (4)

11. Okello J, Kisembo H,Bugeza S, et al. breast cancer detection using sonography in women with mammographically dense breasts . BMC medical journal 2014; 14:41.

12. Disha ED, Kerliu SM, Ymeri H, et al. comparative accuracy of mammography and ultrasound in women with breast symptoms according to age and breast density. Bosnian journal of basic medical sciences 2009; 9(2) :( 131-136).

13. Boyd N.F., Rommens J.M., Vogt K. et al. Mammographic breast density as an intermediate phenotype for breast cancer. Lancet Oncol. 2005;6:798-808.

14. Saarenmaa I., Salminen T., Geiger U. et al. The effect of age and density of the breast on the sensitivity of breast cancer diagnostic by mammography and ultrasonography. Breast Cancer Res.Treat .2001; 67:117-123.

15. Kaplan S.S. Clinical utility of bilateral whole-breast US in the evaluation of women with dense breast tissue. Radiology 2001; 21:641-649.

16. Samardar P, de Paredes ES, Grimes MM, et al . Focal asymmetric densities seen at mammography: US and pathologic correlation. Radiographic 2002; 22:1933. 


\section{مقارنة بين فصص الثي بالاشعة السينية (الماموكر في) والفحص بالموجات فوق الصوتية(سونار الثدي) في كثف سرطان الثدي في

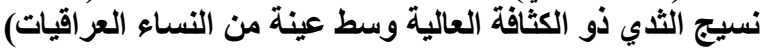

م.د.هبة محمد عبد الواحد

الخلاصة:

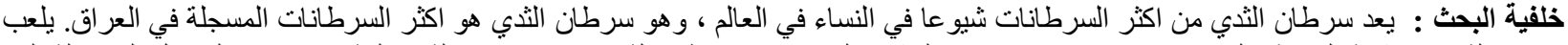

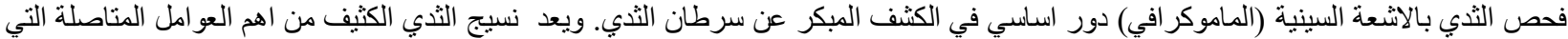

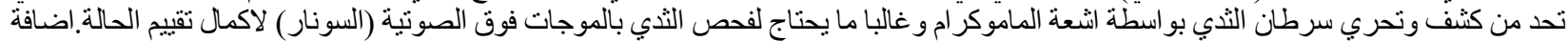

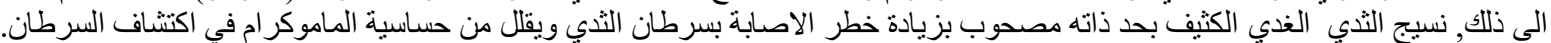

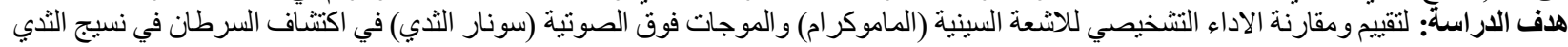
الكثيف.

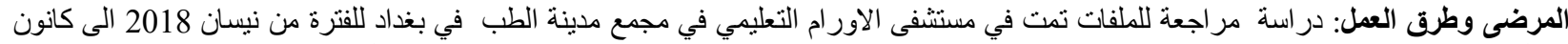

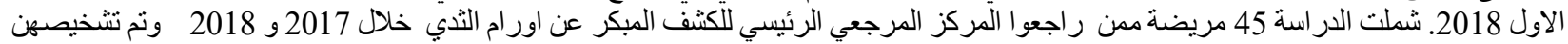

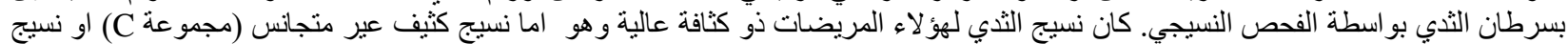

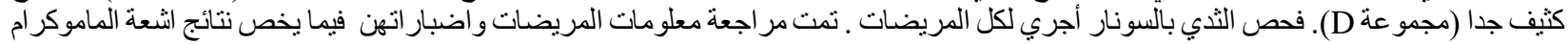

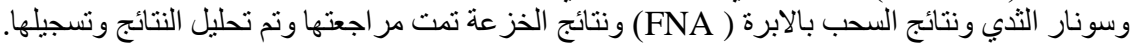

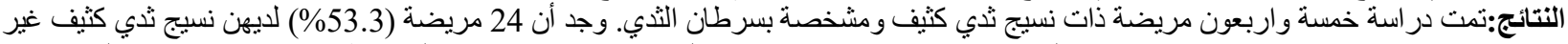

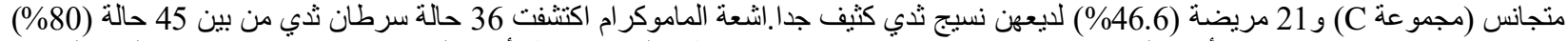

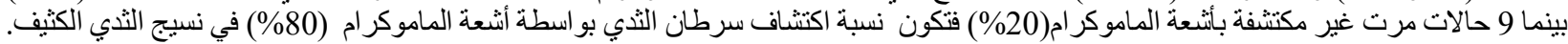

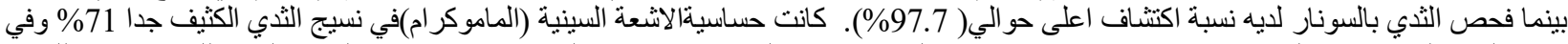

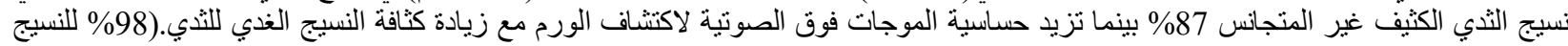

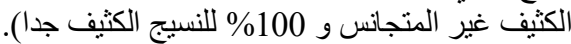
الاستنتاجات: سرطان الثدي ممكن ان يمر غير التهر مشخص في اشعة الماموكر ام للنسيج الغدي الكثيف بسبب تر اكب وتداخل النسيج الغدي للثدي وسونار

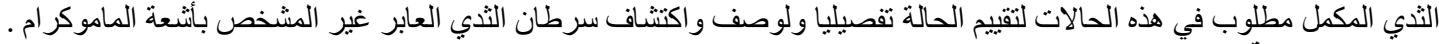
الكلمات المفتاحية: اشعة الثدي(الماموكلافي),فحص بالموجات فوق الصوتية بنسج ذو كثافة عالية, سرطان الثدي المستنر 